\title{
Analysis of the linkages between rainfall and land surface conditions in the West African monsoon through CMAP, ERS-WSC, and NOAA-AVHRR data
}

\author{
Nathalie Philippon \\ Centre de Recherches de Climatologie, CNRS-Université de Bourgogne, Dijon, France
}

Eric Mougin and Lionel Jarlan

Centre d'Etudes Spatiales de la Biosphère, Toulouse, France

Pierre-Louis Frison

Laboratoire des Géomatériaux, l'Institut Francilien des Géosciences, Université de Marne la Vallée, Marne la Vallée, France

Received 21 June 2005; revised 19 September 2005; accepted 20 October 2005; published 31 December 2005.

[1] The European Remote Sensing Wind Scatterometer (ERS-WSC) backscattering coefficient, NOAA Advanced Very High Resolution Radiometer (NOAA-AVHRR) Normalized Difference Vegetation Index (NDVI), and Climate Prediction Center Merged Analysis Precipitation (CMAP) precipitation data sets are studied over the period August 1991 to December 2000 to document (1) the interannual and intra-annual evolutions of vegetation photosynthetic activity and soil-vegetation water content over West Africa and (2) their two-way links with precipitation. Over the Sahel, at interannual timescales the strongest relationships between vegetation, soil moisture, and precipitation are observed from July to October and when 1-month lag is considered between the parameters. This delay reflects the vegetation response time to the moisture pulses that follow precipitation events. The high correlation between NDVI and sigma_0 at interannual timescales confirms the importance of vegetation in the backscattering coefficient. However, sigma_0 shows stronger statistical links with precipitation, suggesting that this product contains additional useful information related in particular to upper soil moisture. Over Guinea, large differences are observed between the two remote sensing products, and their relationship with precipitation at interannual timescales is weaker. Sigma_0 is significantly linked to precipitation from July to November, whereas NDVI does not show any significant relationship with precipitation. NDVI and sigma_0 serial correlations over the Sahel and Guinea suggest that a 2-month memory usually characterizes vegetation photosynthetic activity and soil-vegetation water content anomalies. However, anomalies disappearance in winter then reappearance in the following spring also suggests an interseason memory held by deep soil moisture reservoirs and deep-rooted plants. A composite analysis reveals that the wettest Sahelian rainy seasons were preceded by positive anomalies of soil-vegetation water content over Guinea from winter to spring. Cross correlations and Granger causality analyses partly relate these winter to spring land surface anomalies to those recorded in precipitation during the previous autumn. Spring soil-vegetation water content anomalies strengthen the meridional gradient of soil-vegetation water content over the subcontinent. This gradient is thought to contribute to the gradient of entropy that drives the West African monsoon.

Citation: Philippon, N., E. Mougin, L. Jarlan, and P.-L. Frison (2005), Analysis of the linkages between rainfall and land surface conditions in the West African monsoon through CMAP, ERS-WSC, and NOAA-AVHRR data, J. Geophys. Res., 110, D24115, doi:10.1029/2005JD006394.

\section{Introduction}

[2] In land surface-climate interactions, the potential role of continental forcing on precipitation variability receives increasing interest from the climate scientific community.

Copyright 2005 by the American Geophysical Union. 0148-0227/05/2005JD006394
Among the most recent studies, Koster et al. [2004] point out regions where soil moisture may strongly affect precipitation during northern hemisphere summertime. West Africa is among them.

[3] The West African climate sensitivity to continental surface state partly originates from the monsoon circulation dependence on the meridional gradients of atmospheric 


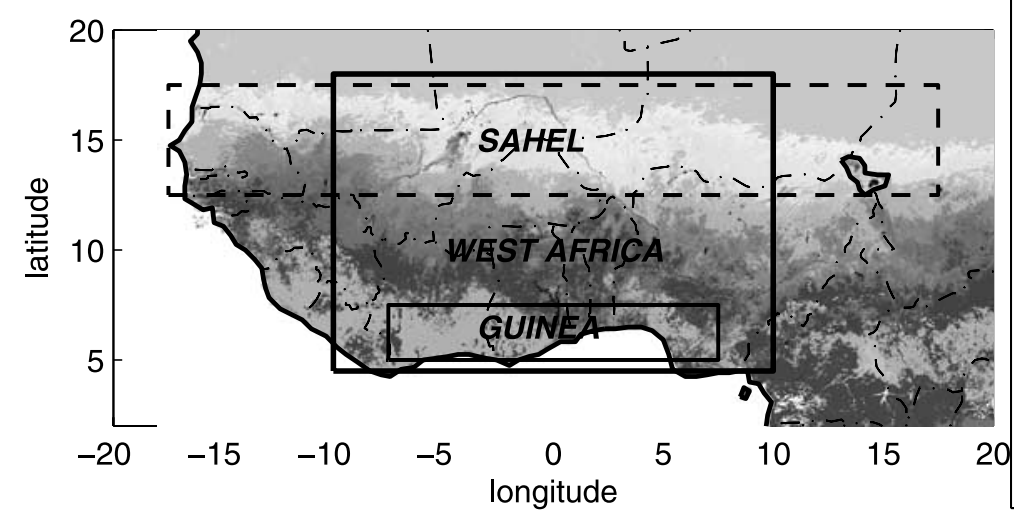

\begin{tabular}{|ll|}
\hline$\square$ & Closed evergreen lowland forest \\
Degraded evergreen lowland forest \\
Montane evergreen forest $(>1000 \mathrm{~m})$ \\
Swamp forest \\
Mangrove \\
Mosaic Forest / Croplands \\
Mosaic Forest / Savanna \\
Closed deciduous forest (Miombo) \\
Deciduous woodland \\
Deciduous shrubland with sparse trees \\
Open deciduous shrubland \\
Closed grassland \\
Open grassland with sparse shrubs \\
Open grassland \\
Sparse grassland \\
Swamp bushland and grassland \\
Croplands ( $>50 \%)$ \\
Croplands with open woody vegetation \\
Irrigated croplands \\
Tree crops \\
Bare soil \\
Salt hardpans \\
Waterbodies \\
Cities
\end{tabular}

Figure 1. Land cover map of West Africa (produced as part of the GLC2000 mapping exercise) and location of the West African (thick solid line), Guinean (thin solid line) and Sahelian (thin dashed line) domains studied. See color version of this figure at back of this issue.

boundary layer entropy [Emanuel et al., 1994; Emanuel, 1995]. Eltahir and Gong [1996] observe large meridional gradient of moist entropy during strong monsoons and wet Sahelian rainy seasons. Fontaine and Philippon [2000] and Fontaine et al. [2002] underline the importance of the gradients evolution from spring to summer. Interannual fluctuations in the meridional gradient have a first-order control by oceanic and continental surfaces on both sides of $5^{\circ} \mathrm{N}$. Negative relationships between July September Sahelian precipitation and the south tropical and equatorial Atlantic sea surface temperatures [Folland et al., 1986; Rowell et al., 1995; Fontaine and Janicot, 1996; Giannini et al., 2003] reflect this oceanic control on monsoon dynamics. The continental control has been examined by Zheng and Eltahir [1998] through coupled experiments in which the vegetation meridional distribution is modified. Deforestation imposed over the coastal region leads to a large reduction of the meridional gradient of moist entropy and leads to a collapse of the monsoon. The strong statistical relationship observed between the July September Sahelian rainy season and the previous September-November Guinean one [Gray et al., 1992; Philippon and Fontaine, 2002] suggests a role for the winter to spring land surface conditions over the Guinean belt. A "interseasonal" memory involving soil wetness, vegetation and the meridional gradient of moist entropy has been hypothesized from diagnostic performed with NCEP/NCAR reanalyzes by Philippon and Fontaine [2002].

[4] The previous numerical and statistical results implied an influence of the land surface conditions (and their potential memory) on the West African monsoon. However, these results are not based on Earth observational data. Among the recent studies that document the West African land surface conditions (LSC hereafter) through such data, few explored LSC intra-annual and interannual evolution regarding those of the Sahelian precipitation in particular. For example Jarlan et al. [2005] extracted four modes of interannual variability over the Sahel region for the summer seasons and found that these modes are related to sea surface temperature anomalies developed in the tropical Atlantic and Indian ocean basins of the preceding autumn and winter. Eklundh and Olsson [2003] detected significant positive trends in the Sahelian vegetation greenness consistent with the precipitation increase observed over the period 1982-1999. This study aims to characterize more precisely the seasonal and interannual evolutions of the West African land surface conditions and their two-way links with precipitation variability. Two different and complementary remote sensing products are used to picture the land surface conditions: the NOAA Advanced Very High Resolution Radiometer (NOAA-AVHRR) Normalized Difference Vegetation Index (NDVI) that documents vegetation photosynthetic activity and the European Remote Sensing Wind Scatterometer (ERS-WSC) backscattering coefficient that captures the soil-vegetation water content. Since ERS-WSC data are only available over August 1991 to December 2000, the study is restricted to this 9-year period. Most of results are presented with a meridional point of view and emphasis is put on the Sahelian and Guinean regions (see Figure 1).

\section{Data and Methods}

\subsection{Data}

2.1.1. ERS-WSC Backscattering Coefficient (Sigma_0)

[5] The first remote sensing product selected to document the West African land surface state comes from the Wind 
Scatterometer instrument (WSC) on board the European Remote Sensing satellite (ERS). That satellite is placed in a near-polar orbit, at a mean altitude of about $780 \mathrm{~km}$, and its inclination is 98.52 degrees (http://earth.esa.int/ printer_friendly/ers/satconc/index.html). The backscattering coefficient (sigma 0 hereafter) measured by the WSC instrument mainly depends upon the dielectric properties of vegetation and soil. For a given frequency, these dielectric properties are closely linked to the vegetation and soil water content [Hallikainen et al., 1985; Ulaby and El-Rayes, 1987]. Sigma_0 also depends on the vegetation density, the relative size of the vegetation components (with respect to the incident wavelength), and soil surface roughness [Ulaby et al., 1982]. Observations made at low incidence angles mainly provide information on soil characteristics, and observations performed at large incidence angles give information about vegetation development because the wave trajectory goes through a larger thickness of the canopy [Frison and Mougin, 1996a]. Consequently, at large incidence angles, if the vegetation density is high, the soil contribution is low. Sigma_0 can be considered as a measure of water content of both vegetation and upper soil, modulated by soil and vegetation roughness. We also use the term "soil-vegetation water content" in the text to refer to sigma_0.

[6] Scatterometer data used in this study were obtained from the European Space Agency during the period August 1991 to December 2000 at a resolution of $0.25^{\circ}$. Monthly images were produced by the following methodology described by Mougin et al. [1995] and Frison and Mougin [1996b]. Data acquired at various incidence angles between 25 and $55^{\circ}$ are attributed to an elementary cell of $0.25^{\circ} \times$ $0.25^{\circ}$ as a function of their longitude/latitude coordinates. Within each cell, a linear fit is used to model the variation of sigma_0 versus incidence angle. Finally, monthly images are produced at a $45^{\circ}$ of incidence angle.

[7] Over the tropical areas, at $45^{\circ}$ incidence angle, maximum values are reached for dense tropical forests: the signal saturates at about $-7.8 \mathrm{~dB}$ because of volume scattering. The lowest values (about $-17 \mathrm{~dB}$ ) are recorded over areas with short and sparse vegetation such as open grasslands. Tropical vegetation with highstanding biomass such as closed semideciduous and degraded evergreen forests also exhibits levels close to saturation during the peak of the growing season. The advantage of the ERSWSC over optical radiometers is that it is nearly insensitive to atmospheric interference and allows monitoring tropical regions that are frequently cloud covered.

\subsubsection{AVHRR-Normalized Difference Vegetation} Index (NDVI)

[8] The second remote sensing product analyzed is the NOAA-Advanced Very High Resolution Radiometer (NOAA-AVHRR) Normalized Difference Vegetation Index (NDVI). It is an empirical index linked to green vegetation photosynthetic activity that allows monitoring vegetation phenology [Tucker, 1979]. It is calculated as the ratio of the difference between the visible and near-infrared channels to their sum. It varies from 0 to 1 for low to high green vegetation density.

[9] Data used in this study were downloaded from the Africa Data Dissemination Service website (http:// igskmncnwb015.cr.usgs.gov/adds) which provides NOAA
16 calibrated NDVI data set from NASA, and latest updates. In version 3 , processed by the Global Inventory Modeling and Mapping Studies (GIMMS) group, data are corrected for intersensor differences, intrasensor degradation, and El Chichon and Mt. Pinatubo volcanic events. They are also intercalibrated with SPOT4-VEGETATION NDVI. Kaufmann et al. [2000], Kaufman et al. [2001], Zhou et al. [2001], and Slayback et al. [2003] highlight the reliability of the data set (e.g., no linear trend or discontinuities detected in time series). The data provided are already synthesized using the Maximum Value Composite (MVC) technique on a 10-day basis. The MVC technique permits the production of nominally cloud free image from individual, partly cloudy input scenes by selecting the most cloudfree pixel from the same geographical location from images taken over a limited period of time. This technique is particularly relevant for the Sahel region. Over the Sahel, precipitation are mostly generated by squall lines, which typically have a 5-day frequency throughout the rainy season. The 10-day MVC technique is expected to ensure clear sky 10-day NDVI values. To compare AVHRR-NDVI and ERS-WSC data, we extrapolated NDVI data from $8 * 8 \mathrm{~km}$ to $48 * 48 \mathrm{~km}$ spatial resolution and calculated monthly means from 10-day averages.

\subsubsection{Precipitation}

[10] Monthly precipitation data were extracted from the Climate Prediction Center Merged Analysis Precipitation (CMAP) database (www.cdc.noaa.gov/cdc/data.cmap.html). We selected the version which merges rain gauges observations with estimates from infrared and microwave satellite data [Xie and Arkin, 1997]. Data are provided on a $2.5^{\circ} \times$ $2.5^{\circ}$ latitude/longitude grid over the period 1979-2003. From both NDVI and precipitation databases, we extracted data relative to the ERS-WSC period spanning from August 1991 to December 2000, and to the West African domain $\left(4^{\circ}-18^{\circ} \mathrm{N} / 18^{\circ} \mathrm{W}-18^{\circ} \mathrm{E}\right)$.

\subsection{Methods}

[11] Correlations, composites, and Granger causality analysis are the three basic methods used to characterize precipitation, vegetation photosynthetic activity, and soilvegetation water content and their statistical linkages at the interannual timescale.

[12] Correlations indicate the extent to which there is a linear statistical relationship between two random variables: they are a scale invariant measure of covariability [Von Storch and Zwiers, 1999]. In this study, correlations are referred as (1) "serial correlation" when they describe relationships in time (e.g., we computed the "serial correlation" of a Sahelian sigma_0 index to assess its similarity at a given time difference) and as (2) "cross correlation" when they describe synchronous or lagged relationships between two variables (e.g., lagged "cross correlations" were computed between NDVI and precipitation indexes to assess vegetation response time to precipitation).

[13] The composite analysis has been used to depict the evolution of sigma_0 and NDVI regarding the Sahelian precipitation. The main advantage of this method is that it is a non parametric method. No assumption is made about the link, linear or not, between the involved variables. It relies on the construction of two samples (in this study, wet and dry years over the Sahel) and computation of their differ- 
ences. The significance of these differences is tested with the Student T-test [Von Storch and Zwiers, 1999].

[14] The last method employed is the Granger causality method that has been recently applied to climate time series analyses [Kaufmann and Stern, 1997; Wang et al., 2004, also manuscript in preparation, 2005]. This method mainly deals with linear prediction and is particularly suitable when the variables are coupled or characterized by strong persistence. It tests whether past values of one variable $Y$ improves the prediction of the current values of a 2 nd variable $X$ compared to prediction only based on past values of $X$ [Enders, 1995]. Thus two predictive models are constructed, a restricted model (equation (1)) and an unrestricted model [Chen et al., 2004, equation (2)] where $\alpha, \beta$ are the regression coefficients, $\varepsilon$ the error terms, and $j$ the lag length.

restricted model:

$$
x(t)=\sum_{j=1}^{m} \alpha_{j} x(t-j)+\varepsilon_{x}(t)
$$

unrestricted model:

$$
x(t)=\sum_{j=1}^{m} \alpha_{j} x(t-j)+\sum_{j=1}^{m} \beta_{j} y(t-j)+\varepsilon_{x \mid t}(t)
$$

The significance of the restrictions in equation (1) relative to equation (2) is tested by the Granger statistic $\omega$ [Kaufmann and Stern, 1997, equation (3)]. In equation (3), $\mathrm{RSS}_{\mathrm{r}}$ and $\mathrm{RSS}_{\mathrm{u}}$ are the sum of the residual squared in the restricted and unrestricted equations, $T$ the number of observations, $k$ the numbers of regressors in the unrestricted equation, and $s$ the number of coefficients set to zero in the restricted equation. The result $\omega$ is distributed with the $F$ distribution with $s$ and $T-k$ degrees of freedom in the numerator and denominator respectively (see Von Storch and Zwiers [1999, pp. 424-430] for distribution tables).

Granger statistic:

$$
\omega=\frac{\left(R S S_{r}-R S S_{u}\right) / s}{R S S_{u} /(T-k)}
$$

\section{Mean Seasonal Evolution of NDVI, Sigma_0, and Precipitation}

\subsection{West African Domain}

[15] The mean seasonal evolutions of precipitation, NDVI, and sigma 0 over the West African domain bounded by longitudes $10^{\circ} \mathrm{W}-10^{\circ} \mathrm{E}$ and latitudes $4^{\circ} \mathrm{N}-18^{\circ} \mathrm{N}$ (Figure 1, solid thick line), are displayed in Figures 2a, $2 \mathrm{~b}$, and $2 \mathrm{c}$, respectively, through time-latitude diagrams. The $10^{\circ} \mathrm{W}-10^{\circ} \mathrm{E}$ domain is homogeneous, characterized by low topography and a zonal distribution of precipitation and vegetation. Figure 1 also provides the latest land cover map of the region produced as part of the Global Land Cover mapping exercise by the Joint Research Centre's Global Vegetation Monitoring Unit (http://www.gvm.jrc.it/glc2000) [Mayaux et al., 2004]. The meridional distribution of the vegetation clearly appears with an increase from north to
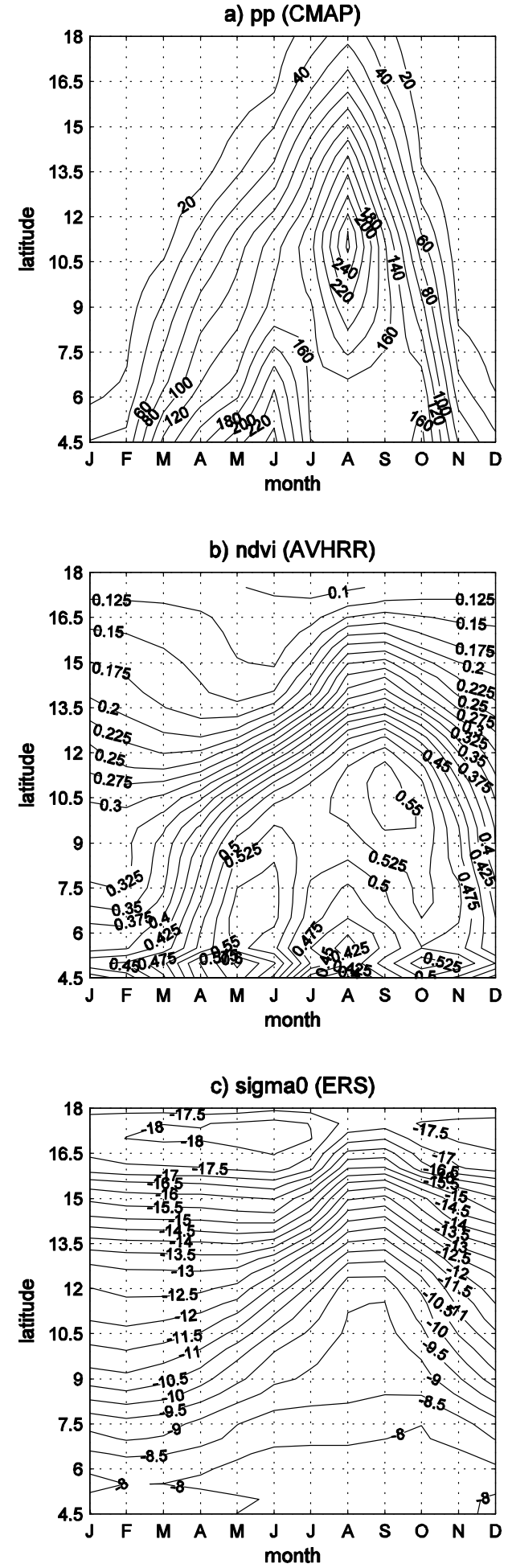

Figure 2. Time-latitude diagrams of mean monthly (a) precipitation (mm), (b) NDVI and (c) sigma_0 (in dB) fields averaged over longitudes $10^{\circ} \mathrm{W}-10^{\circ} \mathrm{E}$ and period August 1991 to December 2000.

south of vegetation density. The Sahelian band encompasses (from north to south) closed grasslands, open deciduous shrublands; thus herbaceous species are dominant. Deciduous shrublands with sparse trees make the transition with the Sudanian domain mainly covered by deciduous open 
a)

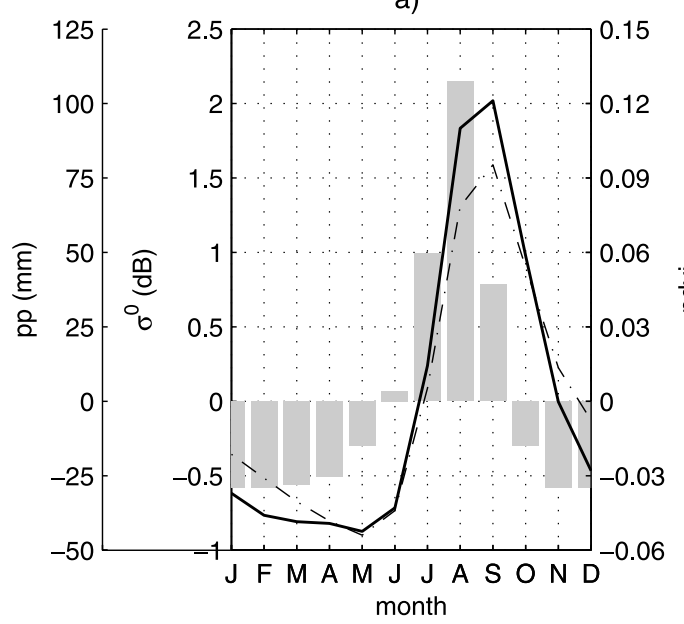

b)

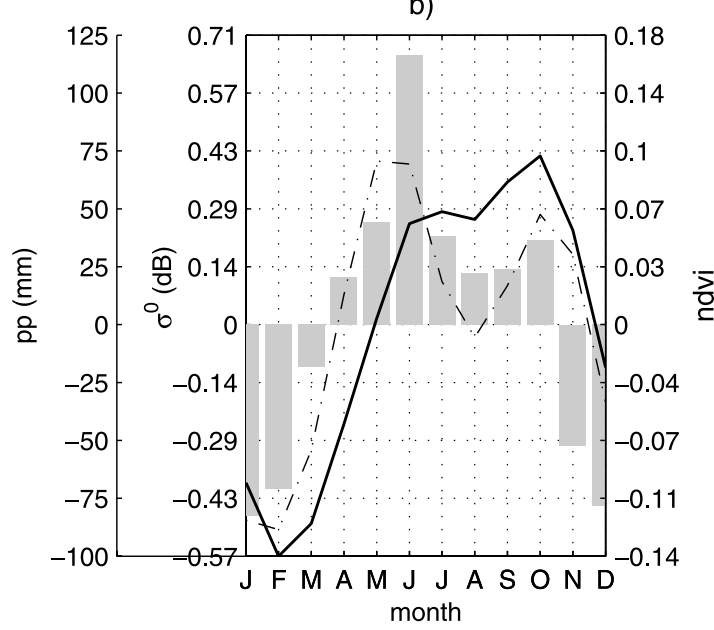

Figure 3. Mean seasonal evolution as departure from the 1991-2000 annual mean, of precipitation (shaded bars, mm), NDVI (thin dash-dot line) and sigma 0 (thick solid line, dB) over (a) Sahel and (b) Guinea. For the Sahel (Guinea), the annual mean of precipitation, NDVI and sigma 0 respectively equals $30 \mathrm{~mm}, 0.2$ and $-14.8 \mathrm{~dB}(94 \mathrm{~mm}, 0.45$ and $-8.4 \mathrm{~dB})$.

woodlands. The deciduous shrublands and open woodlands are mixed with croplands that can represent in some places up to $30 \%$ of the cover. Last, the Guinean region is the domain of the closed semideciduous and degraded evergreen forests. Transition between Sudanian and Guinean domain is through a mosaic of woody formations and croplands. Croplands are also present in the Guinean forests.

[16] Over West Africa, the precipitation annual cycle (Figure 2a) is driven by the meridional displacement of the ITCZ [Sultan and Janicot, 2000, 2003]. The $160 \mathrm{~mm}$ isohyet on Figure 2a can be considered as a good marker of the ITCZ. Its arrival in April at $5^{\circ} \mathrm{N}$ and maintenance at this quasi-stable position till end of June induces the first Guinean rainy season. Then ITCZ abruptly shifts during the first half of July to $10^{\circ} \mathrm{N}$ and remains at this second quasi-stable location until the end of August. At this time, the Sudanian-Sahelian rainy season is fully developed with a core of $240 \mathrm{~mm}$ observed at $11^{\circ} \mathrm{N}$, while the Guinean zone experiences its minor season (less than $160 \mathrm{~mm}$ at $5^{\circ} \mathrm{N}$ ). Last, the ITCZ progressive southward withdrawal from September to November is associated with (1) a sharp precipitation decrease over the Sudanian and Sahelian bands and (2) a precipitation return over Guinea. This constitutes the second rainy season (the $160 \mathrm{~mm}$ isohyet at $4.5^{\circ} \mathrm{N}$ in October).

[17] The mean seasonal evolution of NDVI (Figure 2b) is also characterized by three stages. A first and main core of intense photosynthetic activity (NDVI $>0.55$ ) occurs from April to June around $5^{\circ} \mathrm{N}$, a second one centered on September over $10^{\circ} \mathrm{N}$, and the last one in October over Guinea. These high NDVI levels correspond to the woody formations of the Guinean and Sudanian regions. The three stages roughly coincide in time (except over the SudanianSahelian belt where a lag is observed) and location with those of precipitation. The coincidences indicate the response to precipitation evolution across the annual cycle [Moulin et al., 1997].

[18] The annual cycle of sigma 0 reflects a combination of the upper soil and vegetation water content, and is displayed in Figure 2c. Large negative values correspond to a dry and sparsely covered surface [Frison and Mougin, 1996a]. The sigma 0 cycle is smooth compared to the two preceding parameters. The first rainy season over Guinea (April to June, $5-7.5^{\circ} \mathrm{N}$ ) is associated with a small increase of sigma 0 (less than $1 \mathrm{~dB}$ ). September is the month of maximum soil/vegetation water content over most of West Africa, but over Guinea the maximum is shifted toward October. For Guinea, no marked decrease of sigma_0 is observed during the minor dry season as compared to precipitation and NDVI.

\subsection{Sahelian and Guinean Regions}

[19] The specific mean evolutions of precipitation, NDVI and sigma_ 0 over the Sahel and Guinea, which are of particular interest in this study, are provided in Figure 3. The domains of the two regions are respectively $12.5-$ $17.5^{\circ} \mathrm{N} / 17.5^{\circ} \mathrm{W}-17.5^{\circ} \mathrm{E}$ (Figure 1, thin solid line) and 5$7.5^{\circ} \mathrm{N} / 7.5^{\circ} \mathrm{W}-7.5^{\circ} \mathrm{E}$ (Figure 1, dash-dot line). These boundaries were previously defined by Philippon [2002] and Philippon and Fontaine [2002]. Seasonal cycles are presented as departures from the annual mean to stand out the wet (positive departures) and dry (negative departures) stages as well as their phase.

[20] The Sahel is characterized by a unimodal cycle of precipitation (Figure 3a, shaded bars) with a dry phase spanning from October to May and a wet phase from July to September. The wet (dry) phase peaks in August (February) with a mean precipitation amount of $135 \mathrm{~mm}$. NDVI (dashed line) and sigma 0 (solid line) also present unimodal cycles that respectively range between $0.15-0.29$ and -15.6 to $-12.8 \mathrm{~dB}$. The low phases of the cycles occur from November to July. The high phases are from August to October. Soil-vegetation water content and vegetation photosynthetic activity cycles follow that of precipitation by 1 month. Differences are however perceptible in NDVI and sigma 0 seasonal cycles. These differences refer to the return to the dry stage. Sigma_0 reaches its lowest values as soon as February, whereas NDVI gradually decreases from September to May. This minimum in May does not correspond to any phenological stage. Nicholson et al. 
[1990] ascribe it to signal contamination by the high levels of aerosols and water vapor recorded over the region at this period. The sharp decrease of sigma 0 from September to December must be related to the quick drying of the upper soil and of the annual herbaceous layer [Frison and Mougin, 1996a; Zine et al., 2005].

[21] The lagged response of vegetation photosynthetic activity and soil-vegetation water content over the Sahel in particular has been already documented [Schultz and Halpert, 1995; Shinoda, 1995; Wagner and Scipal, 2000]. Malo and Nicholson [1990], for example, observed that NDVI correlates well with precipitation amounts in the concurrent plus 1 to 2 previous months. Justice et al. [1991], using 10-day composites, highlighted vegetation response time of 10 to 20 days, which tends to increase toward the middle stage of the growing season [Di et al., 1994; Justice et al., 1991].

[22] The lags detected between plant phenology and precipitation can reflect the ecological responses to soil moisture, nutrients pulses generated by precipitation events, sensor spatial resolution, and sensor sampling rate. The type of ecological response depends on the size and duration of the moisture pulses [Schwinning and Sala, 2004] (see their Figure 1). Germination requires small and short soil moisture pulses because it involves a shallow infiltration in the upper soil layer. Plant growth requires pulses on higher orders (weeks to months) since precipitated water has to reach deeper root systems. Over the Sahel, precipitation events are associated with convective storms that are irregular in time and space. Given the low spatial resolution and sampling rate of the two remote sensing products and the high evapotranspiration that limits the persistence of upper soil moisture anomalies, it is not surprising to observe delays between rain gauges records and soil-vegetation water content satellite records [Wagner and Scipal, 2000].

[23] The Guinean region experiences a bimodal precipitation cycle (Figure 3b, bars) with a main dry phase from November to March and a wet phase from April to October. The wet phase has two wet subperiods. The first and main one occurs from April to June with a total amount of $470 \mathrm{~mm}$. The second one is in September-October with a total amount of $240 \mathrm{~mm}$. These two rainy seasons are separated by a precipitation downward trend in July August, the minor dry season. The NDVI cycle (Figure 3b, dashed line) ranges between 0.33 and 0.54 and roughly matches the precipitation cycle, and no temporal lag can be detected between precipitation and vegetation photosynthetic activity, consistent with findings of Nicholson et al. [1990]. For annual precipitation amounts above $1000 \mathrm{~mm}$, precipitation is not an important limiting factor for vegetation growth. In addition, over Guinea, tree density is higher than in the Sahel, as Guinea is mainly covered by deciduous open woodland (Figure 1), and herbaceous plants are perennial. In the West African savanna such as those of Mali and Burkina Faso, tree leaves and perennial grass growth starts before, or at the first precipitation so that, at the onset of the wet season, some species are in full leaf and capable of maximum photosynthetic activity [de Bie et al., 1998]. This is attributed to higher air humidity caused by the arriving monsoon, an access to water stored in deep reservoirs, or even in the plants themselves [de Bie et al., 1998], and a day length increase [Rivera et al., 2002]. This early sprouting might also explain, for the Guinean region, the absence of a delay between NDVI and precipitation, and the rapid increase of NDVI as soon as March. Variations observed in NDVI cycle from July to October are not consistent with moisture conditions or with vegetation phenology. For example, in July and August, NDVI levels tend to be lower than those observed in April whereas precipitation amounts are comparable. Vegetation does not dry out but continues to grow, so that NDVI levels from July to October should be as high as in June. These spurious fluctuations could also be explained by NDVI saturation for high green-leaf density [Tucker et al., 1986], and cloud cover contamination [Gutman, 1999].

[24] With respect to the annual cycle of sigma 0 over Guinea (Figure 3b, solid line) several features can be noted. The range is restricted to -9 to $-8 \mathrm{~dB}$, levels close to the saturation level (see section 2.1.1). From April to July, the sigma_0 cycle exhibits a 1-month lag with precipitation. Over dense and woody vegetated areas, sigma_0 only reacts after the precipitation has increased vegetation canopy cover and water content. The decrease at the time of the minor dry season is negligible, and the maximum is observed in October. Both the canopy cover and its water content are at their maximum over the region in October since the two rainy seasons have occurred. Over Guinea, the sigma_0 cycle is much more coherent with the vegetation growth than NDVI cycle.

\section{Precipitation, NDVI, and Sigma_o Evolutions and Links at Interannual Timescales}

[25] Figure 4 provides the standardized (zero mean and unit variance) time series of NDVI, sigma_0, and precipitation from August 1991 to December 2000, as well as their cross correlations (r1 to $\mathrm{r} 3$ ) for the Sahelian (Figure 4a) and Guinean (Figure $4 b$ ) regions. The seasonal cycles have been removed by setting monthly means to zero.

[26] The Sahelian precipitation variability (Figure 4a, shaded bars) over the period is characterized by the wet years of 1994 and 1999 compared to the dry years of 1996, 1997 and 2000. High variability is also observed in sigma 0 (Figure 4a, solid line) and NDVI (Figure 4a, dashed line). Their anomalies closely track those of precipitation. Sigma 0 is more strongly cross-correlated with precipitation $(\mathrm{r} \overline{1}=0.58)$ than NDVI $(\mathrm{r} 2=0.46)$. These correlation levels illustrate the sensitivity of the herbaceous vegetation to precipitation fluctuations [Gond et al., 1997]. For the Guinean region (Figure 4b), the fitting between precipitation and sigma 0 or NDVI is very weak if not null. Correlations $\mathrm{r} 1$ and $\mathrm{r} 2$ are 0.27 and 0.01 respectively. As previously observed in the mean seasonal cycles (section 3.2 and Figures $3 \mathrm{a}$ and $3 \mathrm{~b}$ ), the closest correlation at interannual timescale between NDVI and sigma $0(\mathrm{r} 3)$ is for the Sahel. The two time series are correlated at 0.8 (versus 0.17 for Guinea). This implies that over the Sahel sigma_0 captures vegetation variability [Frison et al., 1998]. However, its strongest cross correlation with precipitation ( $\mathrm{r} 1>\mathrm{r} 2$ in Figures $4 \mathrm{a}$ and $4 \mathrm{~b})$ also suggests that it contains additional useful information such as soil moisture and vegetation density.

[27] The strength of the relationships between precipitation and the two land surface parameters is seasonally 
a)

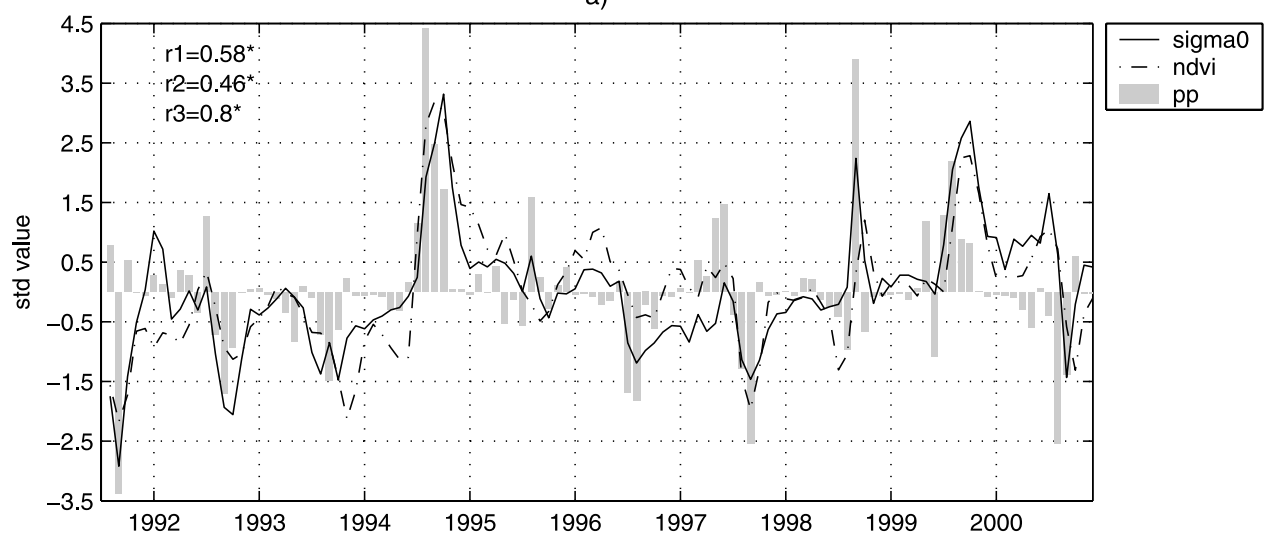

b)

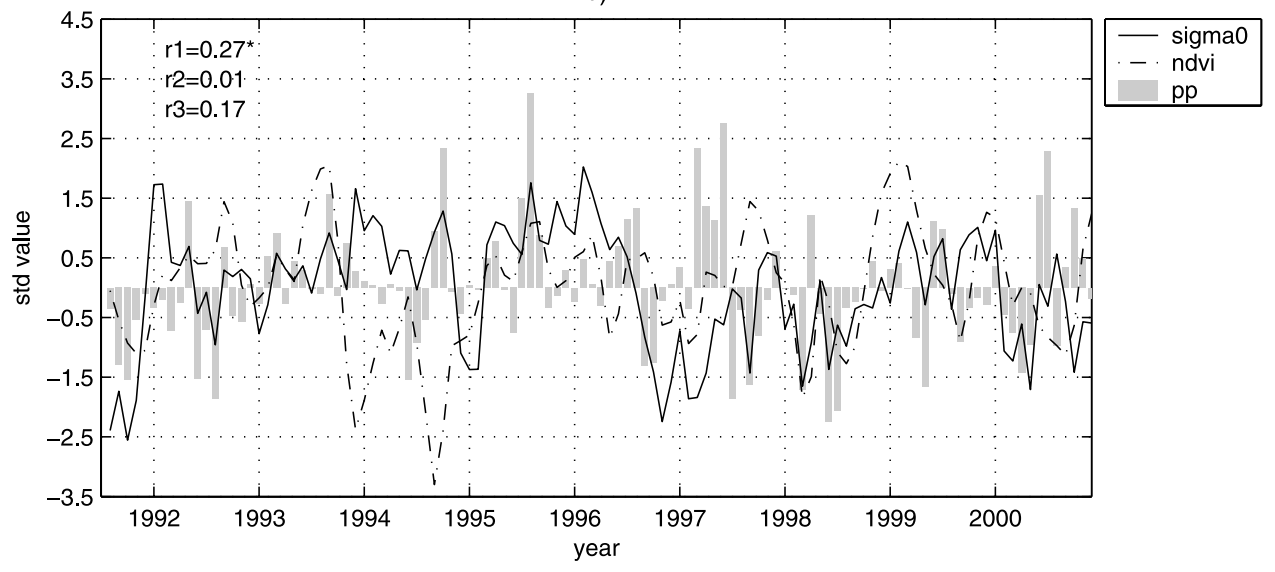

Figure 4. Standardized time series of precipitation (shaded bars), NDVI (dash-dot thin line) and sigma_0 (solid thick line) for (a) Sahel and (b) Guinea over August 1991 to December 2000. Linear cross correlations between sigma_0 and precipitation, NDVI and precipitation, sigma_0 and NDVI, are given by $\mathrm{r} 1, \mathrm{r} 2$ and r3, respectively. Stars denote correlations significant at the $95 \% \overline{\mathrm{level}}$.

dependent. Figure 5 gives monthly cross correlations of precipitation with sigma_0 (solid thick line) and NDVI (dash-dot thin line) at zero (Figures 5a and 5c) and 1 month (Figures $5 \mathrm{~b}$ and $5 \mathrm{~d}$ ) lags for the two West African subregions. Note that in Figures 5-7 and Tables 1 and 2, correlations are computed between time series of 3 months $\times$ 9 years length (i.e., 27 observations). This gives robustness to the results and partly overcomes the problem of few available observations. Over the Sahel (Figures 5a and 5b), precipitation cross correlations with NDVI and sigma_0 are significant from June-July to November, i.e., the time of the rainy and vegetative seasons (Figure 3a). In July November, the two remote sensing products are also highly (and significantly) cross-correlated (Figure 6, shaded bars), sharing more than $70 \%$ of common variance from September to November. Sigma_0 and NDVI have a higher correlation in December than in June possibly related to higher serial correlations (see section 5). However, these results are quite dependent on the space-timescale considered. For example, Jarlan et al. [2002] analyzed data for four sites within the Malian Gourma and Seno regions: Rharous $\left(16.9^{\circ} \mathrm{N}, 1.9^{\circ} \mathrm{W}\right)$, Gossi $\left(15.8^{\circ} \mathrm{N}, 1.3^{\circ} \mathrm{W}\right)$, Hombori $\left(15.3^{\circ} \mathrm{N}, 1.7^{\circ} \mathrm{W}\right)$ and Diankabou $\left(14.6^{\circ} \mathrm{N}, 3.1^{\circ} \mathrm{W}\right)$. For Rharous, Gossi and Hombori sites, an unusual precipitation event in January 1992 (60 $\mathrm{mm}$ in two days) led to a sigma 0 increase in response to short grass development and higher soil moisture. Moreover, results also depend on the type of vegetation, information that is rather smoothed here because of the large scales used. In the case of non natural vegetation, phenology can be partly disconnected from the precipitation cycle particularly at the harvest time.

[28] It is interesting to see that when precipitation is synchronous to (precedes by 1 month) the two land surface parameters (Figures 5a and 5b, respectively), cross correlations with sigma_0 are higher (lower) than with NDVI. Over the Sahel, part of sigma_0 signal is determined by soil moisture, and a more direct relationship exists between precipitation and soil moisture than between precipitation and vegetation photosynthetic activity.

[29] In Guinea (Figures 5c and 5d), relationships between precipitation and sigma_0 and NDVI are weaker than for Sahel. NDVI does not show any significant relationship with precipitation whatever the month (Figures $5 \mathrm{c}$ and $5 \mathrm{~d}$, dash-dot line) whereas sigma_0 is significantly linked to precipitation during the minor dry and beginning of the second wet seasons (Figures 5c and 5d, thick solid line). The closest (and significant) fit between sigma_0 and NDVI (Figure 6, solid line with circles) is observed in March- 
a)

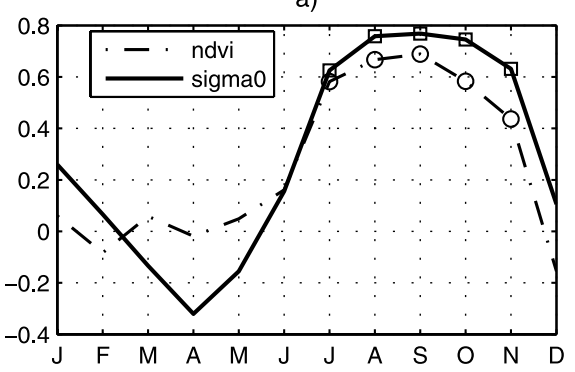

c)

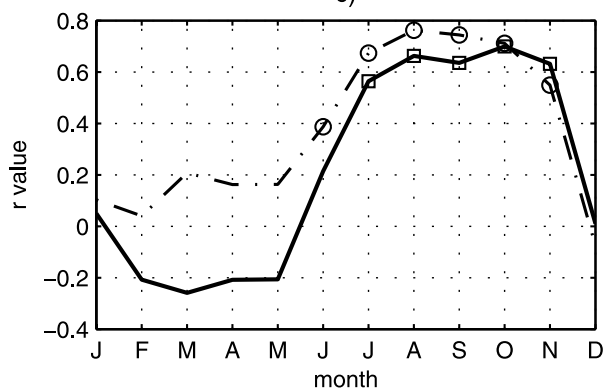

b)

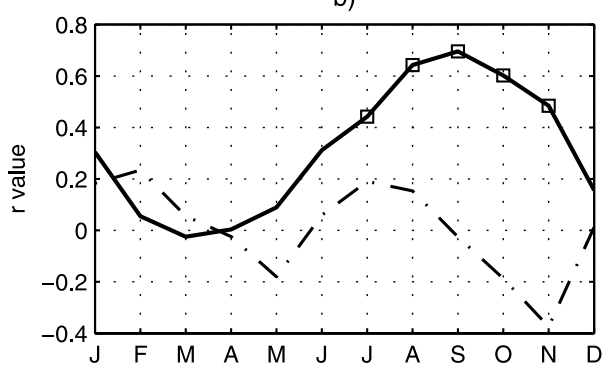

d)

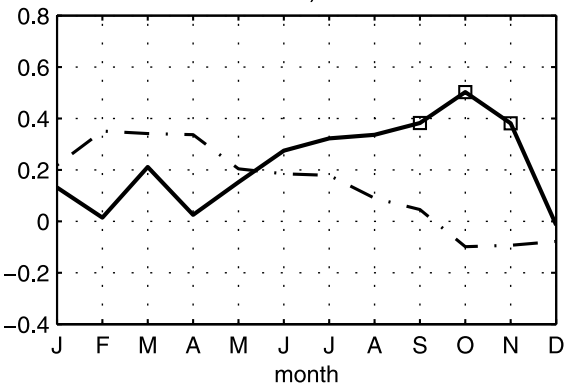

Figure 5. Monthly cross correlations between ( $a$ and b) Sahelian and (c and d) Guinean precipitation indexes and those of sigma_0 (solid thick line) and NDVI (dash-dot thin line) at zero (Figures 5a and 5c) and 1-month lag (Figures $5 \bar{b}$ and $5 \mathrm{~d}$ ). Squares and circles denote correlations significant at the $95 \%$ level.

April, at the time of woody plants sprouting. Accordingly to these results as well as to the closest fit observed between the precipitation and sigma_0 seasonal cycles (see Figure 3), sigma 0 could be more relevant to monitor the response of the land surface to precipitation over Guinea than NDVI.

\section{Memory Effects in Vegetation and Soil Moisture Conditions}

[30] Memory is first estimated through the computation of NDVI and sigma_0 Sahelian and Guinean indices serial correlations. Serial correlation allow to assess similarity at a given time difference (see section 2.2). Figure 7 provides serial correlations (for ranks 1 to 12) obtained when all the observations are considered (i.e., the seasonal cycle phase is not taken into account). For both regions (Sahel (Figure 7a) and Guinea (Figure 7b)), NDVI (dash-dot line), and sigma_0 (solid line) are characterized by strong serial correlations at ranks 1 and 2. For the Sahel, values are somewhat higher (i.e., 0.55 versus 0.45 for Guinea at rank 2). Such a persistence is not observed in precipitation (shaded bars). This partly explains the overall weakness of the precipitation cross correlations with NDVI and sigma_0 in Figures 4a and $4 \mathrm{~b}$. Beginning with rank 3 , values are below 0.3 , which represents less than $10 \%$ of common variance. Thus a 2 month memory seems to characterize vegetation greenness and soil-vegetation water content intra-annual variability over the Sahel and Guinea.

[31] Figure 8 depicts serial correlations as a function of month to assess a possible seasonality in the memory. It must be first noted that, for a given region, NDVI and sigma 0 track each other closely (e.g., compare Figure 8 a to Figure $8 \mathrm{~b}$ ). As already mentioned for Figure 7, the vegetation and upper soil moisture anomalies over the Sahel are the most persistent, particularly for anomalies triggered by the July September rainy season. According to this analysis, NDVI or sigma_0 anomalies observed in SeptemberOctober (i.e., core of the vegetative season, Figures $8 \mathrm{a}, 8 \mathrm{~b}$, and $8 \mathrm{~d}$ ) are still significantly linked to those observed 7 to 9 months later in April-June. The weak serial correlations observed in Figures $8 \mathrm{a}$ and $8 \mathrm{c}$ at lags 3 to 6 suggest that September-October anomalies do not actually persist for

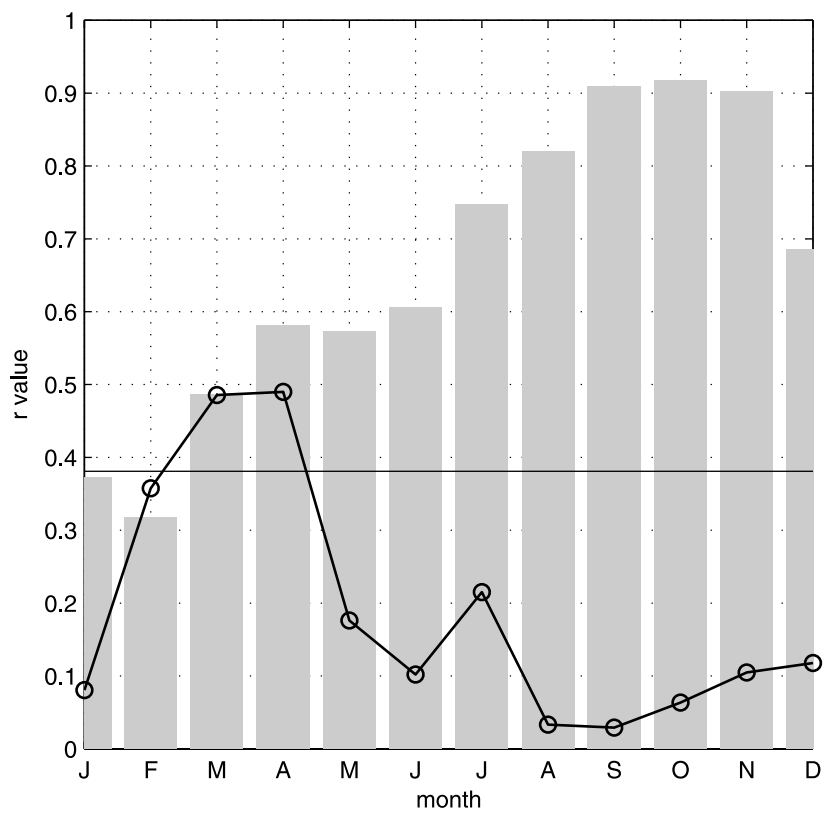

Figure 6. Monthly cross correlation between Sahelian (shaded bars) and Guinean (solid line with circles) indexes of sigma_0 and those of NDVI. Thin line is significance level at $\overline{95} \%$. 
a)

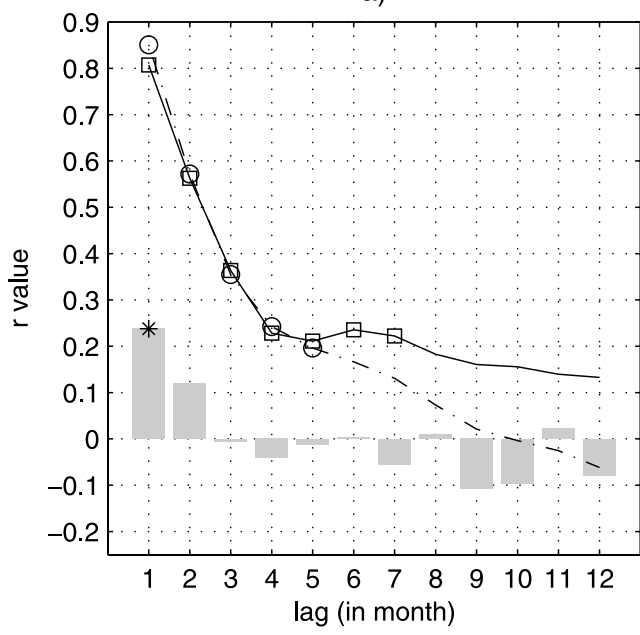

b)

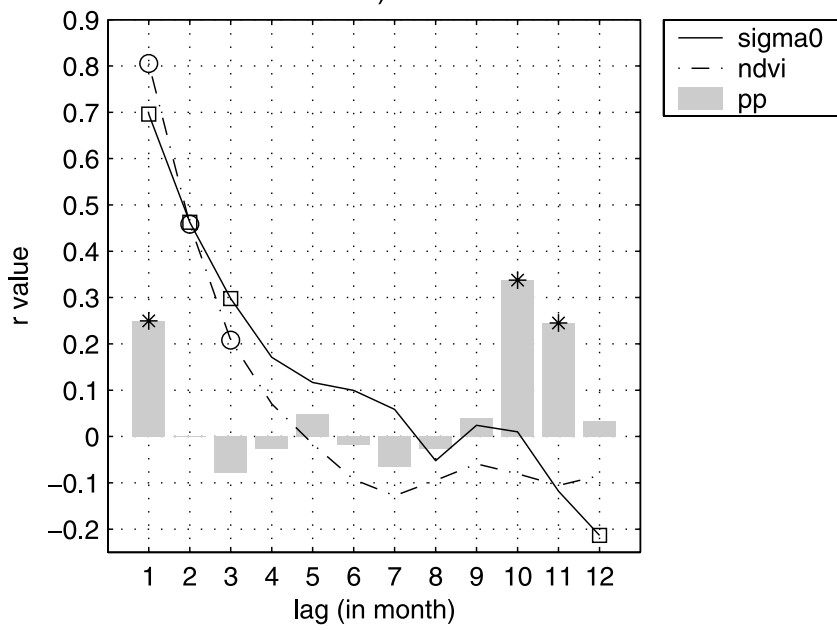

Figure 7. (a) Sahelian and (b) Guinean precipitation (shaded bars), sigma_0 (solid line) and NDVI (thin dashdot line) indexes serial correlation for rank 1 to 12 (in month). Stars, squares and circles denote correlations significant at the $95 \%$ level.

7 months but disappear in winter then reappear in spring. According to Schwinning and Sala [2004], and Schwinning et al. [2004] deep soil moisture can be carried from one year to the next particularly when the annual water input exceeds the vegetation annual uptake capacity. In spring, deep-rooted plants may benefit from this elevated deep soil water

Table 1. Determination Coefficients for Restricted and Unrestricted Equations $\left(r_{r}^{2}\right.$ and $r_{u}^{2}$, Respectively, Columns 2 and 3), Sigma_0 and pp Regression Coefficients for Unrestricted Equations ( $\alpha_{u}$ and $\beta_{u}$, Respectively, Columns 4 and 5), and "Granger Causality" Statistics ( $\omega$ Column 6 ) for Models Where Sigma_0 and pp Lag Spring Sigma_0 From One (i=1, DJF) to Two Seasons $(i=$ 2, SON)

\begin{tabular}{lccccc}
\hline & $\mathrm{r}_{\mathrm{r}}^{2}($ Sigma_0) & $\mathrm{r}_{\mathrm{u}}^{2}($ Sigma_0 $+\mathrm{pp})$ & $\alpha_{u}$ & $\beta_{u}$ & $\omega$ \\
\hline $\mathrm{i}=1$ (DJF) & 0.19 & 0.19 & +0.42 & +0.04 & 0.02 \\
$\mathrm{i}=2$ (SON) & 0.08 & 0.51 & -0.4 & +0.97 & $6.11^{\mathrm{a}}$ \\
\hline
\end{tabular}

\footnotetext{
${ }^{\text {a }}$ Value significant at the $95 \%$ level according to $F$ distribution.
}

Table 2. Cross Correlations Between September to November Precipitation and the Synchronous and Following Sigma_0 3-Monthly Values Over Guinea ${ }^{a}$

\begin{tabular}{ll}
\hline & $\mathrm{r}$ \\
\hline October & $0.6^{\mathrm{b}}$ \\
November & $0.5^{\mathrm{b}}$ \\
December & 0.17 \\
January & 0 \\
February & -0.08 \\
March & 0.3 \\
April & $0.6^{\mathrm{b}}$ \\
May & $0.49^{\mathrm{b}}$ \\
June & $0.52^{\mathrm{b}}$ \\
July & $0.53^{\mathrm{b}}$ \\
August & $0.54^{\mathrm{b}}$ \\
September & $0.5^{\mathrm{b}}$ \\
\hline
\end{tabular}

${ }^{\mathrm{a}}$ Rows indicate the central month of the 3 months considered for computations.

${ }^{\text {b }}$ Correlations significant at the $95 \%$ level.

potentials when they come into leaf [de Bie et al., 1998]. Moreover, observations confirm that tree foliation of one year depends on the quality of the previous rainy season [Hiernaux et al., 1994].

[32] Some differences must be noted between the two regions and the two remote sensing products. Compared to sigma 0 , there is no decrease in NDVI serial correlation for the Sahel in September-October, and the serial correlations are also stronger. In addition, for Guinea, negative relationships are observed between August-October NDVI anomalies and those recorded 6 months later in NDVI versus positive relationships in sigma_0 anomalies. Aerosols, water vapor, and cloud contaminations are likely causes of these differences. They decrease the amount of signal reaching the passive AVHRR instrument. Serial correlations are also globally lower over Guinea than over the Sahel. This could be due to sensor saturation, but also to the greater precipitation and soil moisture and the denser woody-type vegetation observed over Guinea. Dense woodlands and degraded evergreen forests are less vulnerable to dry events.

[33] Using precipitation and NCEP/NCAR data, Philippon and Fontaine [2002] proposed that soilvegetation water content over Guinea in winter and spring depends on the preceding autumn rainy season and could modulate the meridional gradient of moist entropy, affecting the monsoon. This mechanism involves memory effects in Guinea from autumn to spring. The hypothesis of Philippon and Fontaine [2002] is now tested using the two remote sensing data to provide more realistic information on land surface water content than provided by the NCEP/NCAR [Li et al., 2005] reanalyses.

[34] As a first step, we characterized the autumn to summer evolutions of NDVI and sigma_0 regarding Sahelian precipitation variability. This was achieved through a composite analysis (see section 2.2). Results are presented in Figures $9 \mathrm{~b}$ and 9c as differences between the wet minus dry samples. The wet sample is composed of years 1994, 1999 for which the July September Sahelian precipitation anomaly is respectively above the 0.75 standard deviation. The dry sample is composed of years 1996, 1997, 2000 for which the July September Sahelian precipitation anomaly is below the -0.75 standard deviation. For comparison and interpretation purposes, results regarding precipitation are 
a)

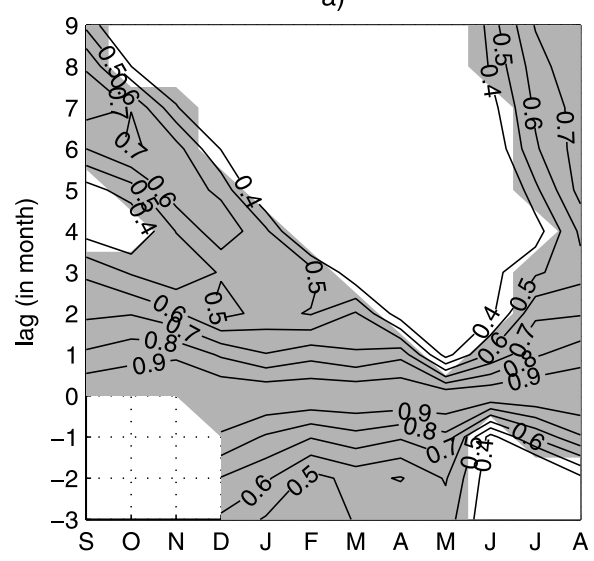

b)

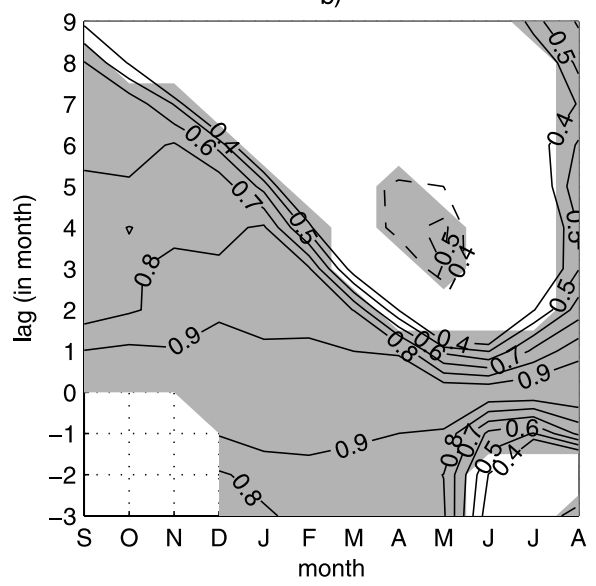

c)

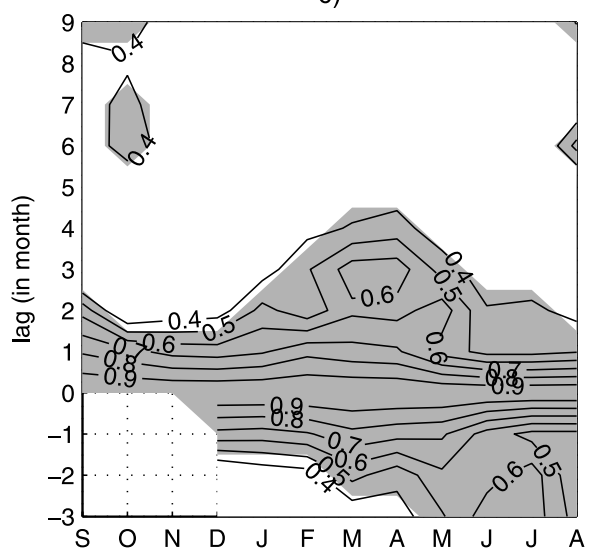

d)

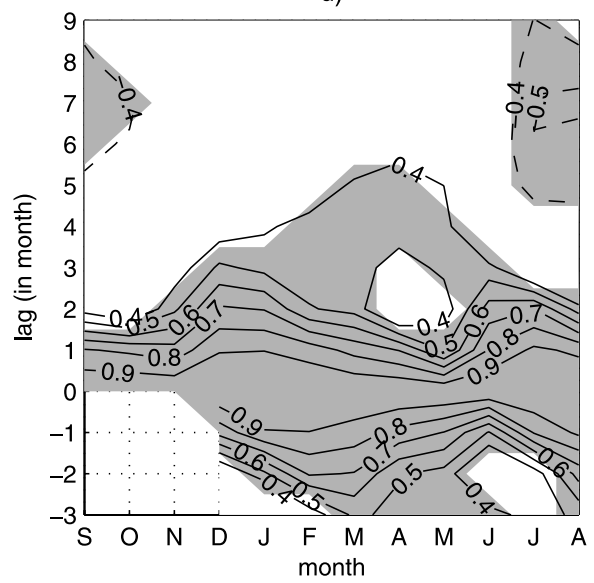

Figure 8. ( $a$ and $b$ ) Sahelian and (c and d) Guinean sigma_0 (Figures 8a and 8c) and NDVI (Figures 8b and $8 \mathrm{~d}$ ) indexes serial correlation as a function of month with lag ranging from -3 to +9 months. Shading denotes correlations significant at the $95 \%$ level.

provided in Figure 9a. The wettest July to September Sahelian rainy seasons are associated with higher vegetation greenness (NDVI, Figure 9b) and soil-vegetation water content (sigma_0, Figure 9c) from August to December. Two additional signals are observed in the months preceding the Sahelian rainy season. The first signal appears in June over the Sudanian band. Lower photosynthetic activity (Figure 9b) and soil-vegetation water content (Figure 9c) are recorded before a wet Sahelian rainy season. These LSC anomalies are associated with synchronous precipitation deficits (Figure 9a). Sudanian indexes of precipitation and sigma_0 are significantly cross-correlated at 0.71 in June. These precipitation anomalies reflect a delayed monsoon northward shift [Fontaine et al., 2002]. The second signal appears as positive anomalies in sigma_0 (Figure 9c) over the Guinea region from January to May. Positive anomalies also appear in NDVI in February but they are not significant. None of the NDVI and sigma_0 signals are associated with synchronous precipitation anomalies, but are preceded by an abnormal wet 2nd Guinean rainy season (Figure 9a, significant positive anomalies in October-November). These autumn to spring signals in precipitation and sigma_0 are consistent with the hypothesis of an interseason memory in the West African monsoon. Over Guinea, at the time of the wet season (April and July to November), NDVI anomalies are frequently opposed to those of precipitation and sigma_0. Once again this could be caused by cloud contamination.

[35] The last step was to evaluate if sigma_0 spring anomalies are related to the autumn precipitation, as the composite analysis is not designed to document this relation. To assess the potential role of autumn precipitation on winter to spring sigma_0 variability, we used the Granger causality method (see section 2.2 ). We performed predictions of the March-May values of sigma_0 based on its past measurements (those of September-November and December-February, SON and DJF hereafter). These are the restricted models. Then, we compared these predictions to those based both on past values of sigma_0 and past values of precipitation. These are the unrestricted models. The null hypothesis in this study is that the autumn or winter precipitation values do not improve the prediction of sigma_0 spring values. The main results and statistics of the Granger analysis are presented in Table 1. The results of cross correlations computed between the Guinean SON precipitation and the synchronous and following 3-monthly values of sigma_0 are given in Table 2 .

[36] All the results suggest that autumn precipitation could be an important contributor to sigma 0 variability in spring. In Table 1, it appears that the null hypothesis must 
a)

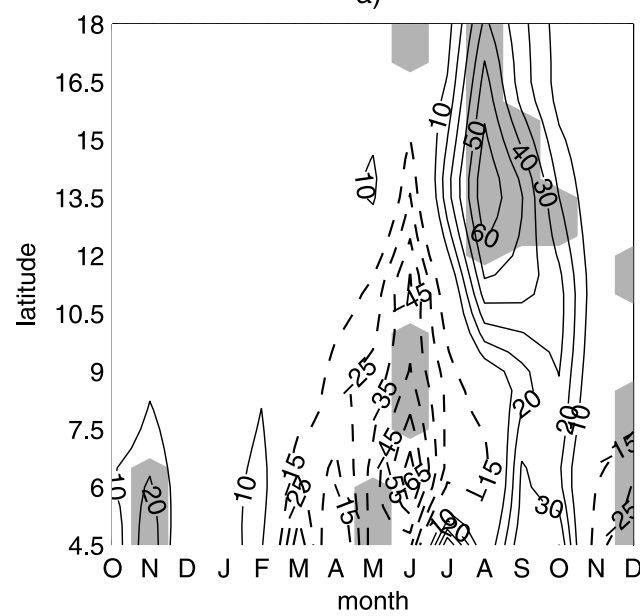

b)

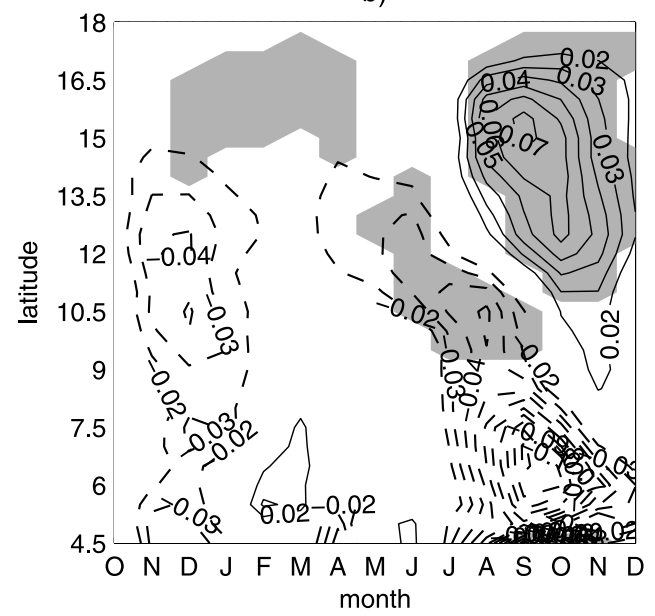

c)

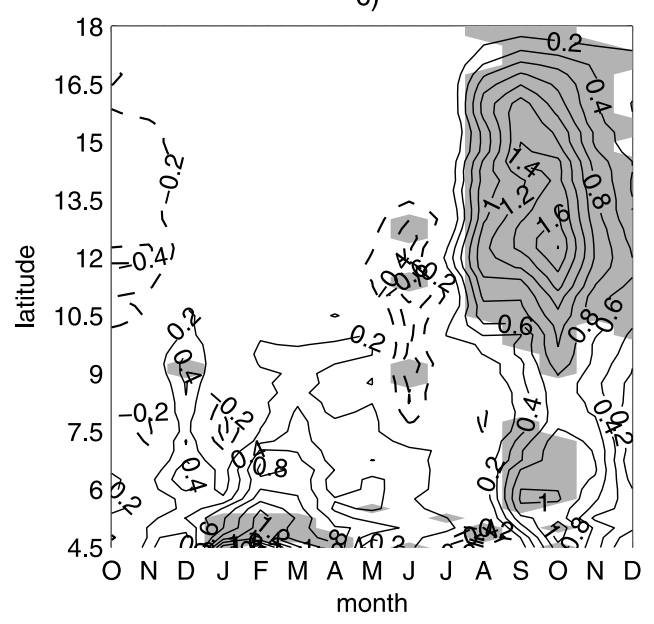

Figure 9. Time-latitude diagrams of the wet minus dry composite of (a) precipitation, (b) NDVI and (c) sigma 0 fields averaged over longitudes $10^{\circ} \mathrm{W}-10^{\circ} \mathrm{E}$ from October of year $I-1$ to December of year $i$. Solid (dashed) lines give positive (negative) differences (in $\mathrm{mm}$ for precipitation and natural values*100 for sigma_0) between the two samples. Shading denotes differences significant at the 95\% level (Student t-test). be rejected for the SON season (3rd line, last column, $\omega$ is significant). The SON precipitation significantly contributes to predict MAM sigma 0 and the two time series are correlated at 0.6 (Table 2). The positive signs of the regression (Table 1, column 5) and cross correlation (MAM, Table 2) coefficients indicate that above normal precipitation in autumn are generally followed by higher soil-vegetation water content in spring. According to Schwinning and Sala [2004] and Schwinning et al. [2004], the memory mechanism involves deep soil moisture reservoirs and deep-rooted plants. Guinea is mainly covered by a mosaic of forest, savannah and cropland (see Figure 1 and section 3.1).

[37] A key parameter for the West African monsoon is the meridional gradient of entropy that develops between the tropical South Atlantic and the subcontinent. This gradient drives the monsoon. Its strength is related to the sea surface temperature distribution over the South Atlantic and the vegetation distribution over the continent [Zheng and Eltahir, 1998; Zheng et al., 1999]. At decadal timescales, variations of the gradient of entropy over the continent can be related to large-scale modifications of the land cover. At interannual and intra-annual timescales, the strength of the gradient could be partly controlled by soil-vegetation water content anomalies such as those highlighted in Figure 9c.

[38] Figure 10 presents the intra-annual evolution of a sigma_0 meridional gradient computed as the difference between the Guinean and Sahelian bands within longitudes $10^{\circ} \mathrm{W}-10^{\circ} \mathrm{E}$. Its mean evolution is displayed as a solid thin line. The highest soil-vegetation water content gradient over West Africa is observed in June $(\sim 7.3 \mathrm{~dB})$ when the soilvegetation water content over Sahel is at its minimum (see Figure 2a). The start of the Sahelian rainy season marks a gradient decrease reaching its minimum $(\sim 4.8 \mathrm{~dB})$ in September. From October to December, with the southward

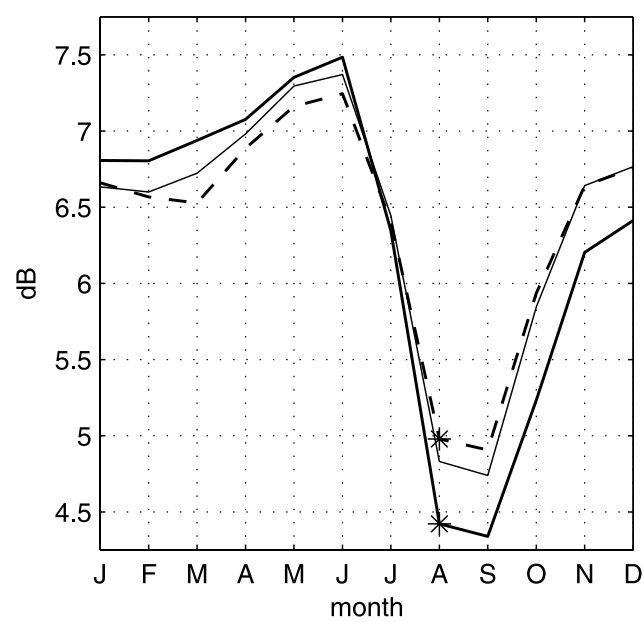

Figure 10. Annual evolution of the wet (solid thick line) and dry (dashed thick line) composites of a backscattering coefficient meridional gradient computed as the difference between the Guinean $\left(5-7.5^{\circ} \mathrm{N}\right)$ and Sahelian (12.5$17.5^{\circ} \mathrm{N}$ ) bands averaged over longitudes $10^{\circ} \mathrm{W}-10^{\circ} \mathrm{E}$. Stars denote month when differences between wet and dry samples are significant at the 90\% level (Student t-test). The solid thin line displays the mean seasonal cycle. 
monsoon withdrawal, the gradient strengthens anew and reaches $\sim 6.7 \mathrm{~dB}$. Last, from January to March, the monsoon air mass no longer affects the region, and the dry season occurs over the Sahel and Guinea, producing the slight decrease observed $(\sim 6 \mathrm{~dB})$.

[39] The solid thick and dashed thin lines in Figure 10 respectively give the gradient evolution during the wettest and driest Sahelian rainy seasons. The wettest (driest) rainy seasons are usually preceded in winter and spring by a larger (flatter) gradient. The largest differences between the two samples are in February-March when strong and significantly positive anomalies of soil-vegetation water content are experienced over Guinea (see Figure 9c). In winter and spring, the maximum of entropy is recorded over the Guinean coast and Guinean Gulf regions, while the minimum is located over the Sahara [Philippon, 2002]. Therefore a larger meridional gradient of soil-vegetation water content over the continent, as induced by positive anomalies of soil-vegetation water content over Guinea, is expected to enhance the meridional gradient of entropy. In summer, the wettest Sahelian rainy seasons are associated with a flatter gradient.

[40] Main signals have been highlighted with regard to the interseason memory hypothesis proposed by Philippon and Fontaine [2002]. These empirical observational results argue for several additional studies. The number of available observations in this study was limited to 9. Results have to be confirmed through other Earth observational products of soil-vegetation water content covering a different period. The soil moisture product from the Advanced Scanning Microwave Radiometer on board Earth Observing System Aqua platform (ASMR-E [Koike et al., 2004]) is a good candidate. The Soil Moisture and Ocean Salinity mission to come (SMOS [Kerr et al., 2001]) should also deliver more reliable soil moisture fields at space-timescales of particular interest for such land - atmosphere interactions studies. Winter to spring anomalies in the land surface conditions over Guinea are assumed to impact on monsoon settlement and development through a modification of the meridional gradient of entropy. This must be further explored through new numerical experiments.

\section{Conclusion}

[41] The interannual and intra-annual evolutions of vegetation photosynthetic activity and soil-vegetation water content over West Africa, and their relation with precipitation have been studied through three independent data sets: ERS-WSC backscattering coefficient, NOAA-AVHRR NDVI, and CMAP precipitation over the period August 1991 to December 2000. The first two sets of analyses emphasized the NDVI and sigma 0 responses to precipitation variations at seasonal and interannual timescales, comparing the two remote sensing products making regional comparisons between the Sahel and Guinea.

[42] Over the Sahel, NDVI and sigma 0 mean seasonal cycles roughly coincide, and both follow precipitation with a 1-month lag. At interannual timescales, precipitation relationships with vegetation and upper soil moisture are highly season-dependent. The strongest relationships are observed at the time of the rainy and vegetative seasons, i.e., July to October and when 1-month lag is considered between the parameters. This delay reflects the vegetation response time to the moisture pulses that follow precipitation. The correlation between NDVI and sigma_0 at interannual timescales $(r>0.8)$ confirms the importance of vegetation contribution to the backscattering coefficient. However, sigma_0 shows stronger statistical links with precipitation. This suggests that this product contains additional useful information related in particular to upper soil moisture, regarding the Sahelian land surface state and its sensitivity to precipitation. Over Guinea, large differences are observed between the two remote sensing products and their relationship with precipitation at interannual timescales is globally weak. The sigma_0 seasonal cycle is consistent with moisture conditions and vegetation growth cycles, i.e., a maximum in October and a limited decrease at the time of the minor dry season. NDVI exhibits from July to October spurious fluctuations that appear to be related to atmospheric contamination. Sigma_0 is significantly linked to precipitation from July to November, whereas NDVI does not show any significant relationship with precipitation whatever the month. Except for sigma 0 at the beginning of the wet season, no delay is observed in the LSC response time to precipitation.

[43] The third set of analysis was specifically devoted to the detection of possible land surface memory effects in the West African monsoon following the hypothesis of Philippon and Fontaine [2002]. NDVI and sigma_0 serial correlations over the Sahel and Guinea suggest that a 2-month memory usually characterizes vegetation photosynthetic activity and soil-vegetation water content anomalies. However, anomalies that follow the wet seasons are prone to maintain for longer periods. Their disappearance in winter then reappearance in the following spring suggests that the theoretical interseason memory held by deep soil moisture reservoirs and deep-rooted plants is possible. Such interseason memory could play a role in the Sahelian precipitation variability. A composite analysis reveals that, over the study period, the wettest Sahelian rainy seasons were preceded by positive anomalies of soil-vegetation water content over Guinea from winter to spring. Cross correlations and Granger causality analyses partly relate these winter to spring land surface anomalies to those recorded in precipitation during the previous autumn. Spring soil-vegetation water content anomalies strengthen the meridional gradient of soil-vegetation water content over the subcontinent. This gradient is thought to contribute to the gradient of entropy that drives the West African monsoon. Fields measurements planned during the Extended Observational Period of the African Monsoon Multidisciplinary Analyses multinational program (AMMA, http://amma.mediasfrance.org/france/) should help at documenting these points.

[44] Acknowledgments. Authors are grateful to the members of CRC and the anonymous reviewers for their useful comments. This research has been supported by "ECCO-PNRH," a contribution to the French national program "ACI-FNS ECCO." L.J. and N.P. thank CNES for providing them with fellowships.

\section{References}

Chen, Y., G. Rangarajan, J. Feng, and M. Ding (2004), Analysing multiple nonlinear time series with extended Granger causality, Phys. Lett. A, 324, $26-35$. 
de Bie, S., P. Ketner, M. Paasse, and C. Geerling (1998), Woody plant phenology in the West Africa savanna, J. Biogeogr., 25(5), 883-900, doi:10.1046/j.1365-2699.1998.00229.x.

Di, L., D. C. Rundquist, and L. Ham (1994), Modeling relationships between NDVI and precipitation during vegetative growth cycles, Int. J. Remote Sens., 15, 2121-2136.

Eklundh, L., and L. Olsson (2003), Vegetation index trends for the African Sahel 1982-1999, Geophys. Res. Lett., 30(8), 1430, doi:10.1029/ 2002GL016772.

Eltahir, E. A. B., and C. Gong (1996), Dynamics of wet and dry years in West Africa, J. Clim., 9, 1030-1042.

Emanuel, K. A. (1995), On thermally direct circulations in moist atmospheres, J. Atmos. Sci., 52, 1529-1534.

Emanuel, K. A., J. D. Neelin, and C. S. Bretherton (1994), On large-scale circulations in convecting atmosphere, Q. J. R. Meteorol. Soc., 120 $1111-1143$.

Enders, W. (1995), Applied Econometric Time Series, John Wiley, Hoboken, N. J.

Folland, C. K., T. N. Palmer, and D. E. Parker (1986), Sahel rainfall and worldwide sea temperature 1901-1985, Nature, 320, 602-607.

Fontaine, B., and S. Janicot (1996), Near-global sea surface temperature variability associated with West African anomaly types, J. Clim., 9 , $2935-2940$

Fontaine, B., and N. Philippon (2000), Seasonal evolution of boundary layer heat content in the West African monsoon from the NCEP/NCAR reanalyses (1968-1998), Int. J. Climatol., 20, 1777-1790.

Fontaine, B., N. Philippon, S. Tzraska, and P. Roucou (2002), Spring to summer changes in the West African monsoon through NCEP/ NCAR reanalyses (1968-1998), J. Geophys. Res., 107(D14), 4186, doi:10.1029/2001JD000834.

Frison, P. L., and E. Mougin (1996a), Monitoring global vegetation dynamics with ERS-1 wind scatterometer data, Int. J. Remote Sens., 17(16), $3201-3218$.

Frison, P. L., and E. Mougin (1996b), Use of ERS-1 wind scatterometer data over land surfaces, IEEE Trans. Geosci. Remote Sens., 34(2), 550560.

Frison, P. L., E. Mougin, and P. Hiernaux (1998), Observations and interpretation of seasonal ERS-1 Wind Scatterometer data over Northern Sahel (Mali), Remote Sens. Environ., 693, 233-242.

Giannini, A., R. Saravanan, and P. Chang (2003), Oceanic forcing of Sahel rainfall on interannual to interdecadal time scales, Science, 302(5647), $1027-1030$

Gond, V., J. Fontès, and P. Loudjani (1997), African biomes dynamic by remote sensing temporal analysis, C. R. Acad. Sci., 320, 179188

Gray, W. M., C. W. Landsea, P. W. Mielke, and K. J. Berry (1992), Predicting Atlantic seasonal hurricane activity 6-11 months in advance, Weather Forecasting, 7, 440-455.

Gutman, G. G. (1999), On the use of long-term global data of land reflectances and vegetation indices from the Advanced Very High Resolution Radiometer, J. Geophys. Res., 104, 6241-6255.

Hallikainen, M. T., F. T. Ulaby, M. C. Dobson, M. A. El-Rayes, and L.-K. Wu (1985), Microwave dielectric behavior of wet soil. part I: Empirical models and experimental observations, IEEE Trans. Geosci. Remote Sens., 23, 25-34

Hiernaux, P. H. Y., M. I. Cissé, L. Diarra, and P. N. de Leeuw (1994), Fluctuations saisonnières de la feuillaison des arbres et buissons sahéliens. Conséquences pour la quantification des ressources fourragères, Rev. Elev. Med. Vet. Pays Trop., 47(1), 117-125.

Jarlan, L., E. Mougin, P. L. Frison, P. Mazzega, and P. Hiernaux (2002), Analysis of ERS wind scatterometer time series over Sahel (Mali), Remote Sens. Environ., 81, 404-415.

Jarlan, L., Y. M. Tourre, E. Mougin, N. Philippon, and P. Mazzega (2005), Dominant patterns of AVHRR NDVI interannual variability over the Sahel and linkages with key climate signals (1982-2003), Geophys. Res. Lett., 32, L04701, doi:10.1029/2004GL021841.

Justice, C. O., G. Dugdale, J. R. Townshend, A. S. Narracott, and M. Kumar (1991), Synergism between NOAA-AVHRR and Meteosat data for studying vegetation development in semi-arid West Africa, Int. J. Remote Sens., 12, 1349-1368.

Kaufman, Y. J., D. Tanre, O. Dubovik, and A. Karnieli (2001), Absorption of sunlight by dust as inferred from satellite and ground-based remote sensing, Geophys. Res. Lett., 28(24), 4531-4534.

Kaufmann, R. K., and D. I. Stern (1997), Evidence for human influence on climate from hemispheric temperature relations, Nature, 388, 3944.

Kaufmann, R. K., L. Zhou, Y. Knyazikhin, N. Shabanov, R. Myneni, and C. J. Tucker (2000), Effect of orbital drift and sensor changes on the time series of AVHRR vegetation index data, IEEE Trans. Geosci. Remote Sens., 38, 2584-2597.
Kerr, Y. H., P. Waldteufel, J. P. Wigneron, J. M. Martinuzzi, J. Font, and M. Berger (2001), Soil moisture retrieval from space: The Soil Moisture and ocean Salinity (SMOS) mission, IEEE Trans. Geosci. Remote Sens., 39, 1729-1735.

Koike, T., Y. Nakamura, I. Kaihotsu, G. Davva, N. Matsuura, K. Tamagawa, and H. Fujii (2004), Development of an Advanced Microwave Scanning Radiometer (AMSR-E) algorithm of soil moisture and vegetation water content, Annu. J. Hydraul. Eng. JSCE, 48(2), 217-222.

Koster, R. D., et al. (2004), Regions of strong coupling between soil moisture and precipitation, Science, 305, 1138-1140.

Li, H., A. Robock, S. Liu, X. Mo, and P. Viterbo (2005), Evaluation of reanalysis soil moisture simulations using updated Chinese soil moisture observations, J. Hydrometeorol., 6, 180-193.

Malo, A. R., and S. Nicholson (1990), A study of the rainfall and vegetation dynamics in the African Sahel using the normalised difference vegetation index, J. Arid Environ., 19, 1-24.

Mayaux, P., E. Bartholomé, S. Fritz, and A. Beward (2004), A new landcover map of Africa for the year 2000, J. Biogeogr., 31, 861-877.

Mougin, E., A. Lopes, P. L. Frison, and C. Proisy (1995), Preliminary analysis of ERS-1 wind scatterometer data over land surfaces, Int. J. Remote Sens., 6, 391-398.

Moulin, S., L. Kergoat, N. Viovy, and G. Dedieu (1997), Global-scale assessment of vegetation phenology using NOAA/AVHRR satellite measurements, J. Clim., 10, 1154-1170.

Nicholson, S., M. Davenport, and A. R. Malo (1990), A comparison of the vegetation response to rainfall in the Sahel and East Africa using Normalized Difference Vegetation Index from NOAA AVHRR, Clim. Change, 17, 209-241.

Philippon, N. (2002), A new approach regarding seasonal rainfall statistical forecasting for West and East Africa: Methods, diagnoses (1968-1998) and real-time applications (2000-2001), Ph.D. thesis, 241 pp., Univ. of Burgundy, Dijon, France.

Philippon, N., and B. Fontaine (2002), The relationship between the Sahelian and previous 2 nd Guinean rainy seasons: a monsoon regulation by soil wetness?, Ann. Geophys., 20, 575-582.

Rivera, G., S. Elliott, L. S. Caldas, G. Nicolossi, V. T. R. Coradin, and R. Borchert (2002), Increasing-day length induces spring flushing of tropical dry forest trees in the absence of rain, Trees, 16, 445-446, doi:10.1007/s00468-002-0185-3.

Rowell, D. P., C. K. Folland, K. Maskell, and M. N. Ward (1995), Variability of summer rainfall over tropical North Africa (19061992): Observations and modelling, O. J. R. Meteorol. Soc., 121, $669-704$.

Schultz, P. A., and M. S. Halpert (1995), Gloval analysis of the relationships among a vegetation index, precipitation and land surface temperature, Int. J. Remote Sens., 16, 2755-2777.

Schwinning, S., and O. E. Sala (2004), Hierarchy of responses to resource pulses in arid and semi-arid ecosystems, Oecologia, 141, 211-220.

Schwinning, S., O. E. Sala, M. E. Loik, and J. R. Ehleringer (2004), Thresholds, memory and seasonality: Understanding pulse dynamics in arid/semi-arid ecosystems, Oecologia, 141, 191-193.

Shinoda, M. (1995), Seasonal phase lag between rainfall and vegetation activity in tropical Africa as revealed by NOAA satellite data, Int. J. Climatol., $15,565-639$.

Slayback, D. A., J. E. Pinzon, S. O. Los, and C. Tucker (2003), Northern Hemisphere photosynthetic trends 1982-1999, Global Change Biol., 9, $1-15$.

Sultan, B., and S. Janicot (2000), Abrupt shift of the ITCZ over West Africa and intra-seasonnal variability, Geophys. Res. Lett., 27(18), 3353-3356.

Sultan, B., and S. Janicot (2003), The West African monsoon dynamics. Part II: The "preonset" and "onset" of the summer, J. Clim., 16, 34073427.

Tucker, C. (1979), Red and photographic infrared linear combinations for monitoring vegetation, Remote Sens. Environ., 8, 127-150.

Tucker, C. J., C. O. Justice, and S. D. Prince (1986), Monitoring the grasslands of the Sahel 1984-1985, Int. J. Remote Sens., 7(11), $1571-1581$.

Ulaby, F. T., and M. A. El-Rayes (1987), Microwave dielectric spectrum of vegetation. Part II: Dual-dispersion model, IEEE Trans. Geosci. Remote Sens., 25, 550-557.

Ulaby, F. T., R. K. Moore, and A. K. Fung (1982), Microwave Remote Sensing: Active and Passive, Addison-Wesley, Boston, Mass.

Von Storch, H., and F. W. Zwiers (1999), Statistical Analysis in Climate Research, 484 pp., Cambridge Univ. Press, New York.

Wagner, W., and K. Scipal (2000), Large-scale soil moisture mapping in western Africa using the ERS scatterometer, IEEE Trans. Geosci. Remote Sens., 28(4), 1777-1782.

Wang, W., B. Anderson, R. K. Kaufmann, and R. B. Myneni (2004), On the relation between the North Atlantic Oscillation and SSTs in the North Atlantic basin, J. Clim., 17, 4752-4759. 
Xie, P., and P. Arkin (1997), Global precipitation: A 17-year monthly analysis based on gauge observations, satellite estimates and numerical model outputs, Bull. Am. Meteorol. Soc., 78, 2539-2558.

Zheng, X., and E. A. B. Eltahir (1998), The role of vegetation in the dynamics of West African monsoon, J. Clim., 11, 2078-2096.

Zheng, X., E. A. B. Elathir, and K. A. Emanuel (1999), A mechanism relating tropical Atlantic spring sea surface temperature and West African rainfall, Q. J. R. Meteorol. Soc., 125, 1129-1163.

Zhou, L., C. J. Tucker, R. K. Kaufmann, D. Slayback, V. S. Shabanov, and R. B. Myneni (2001), Variations in northern vegetation activity inferred from satellite data of vegetation index during 1981 to 1999 , J. Geophys. Res., 106, 20,069-20,084.

Zine, S., L. Jarlan, P. L. Frison, E. Mougin, P. Herniaux, and J. P. Rudan (2005), Land-surface parameter monitoring with ERS scatterometer data over the Sahel: A comparison between agro-pastoral and pastoral areas, Remote Sens. Environ., 96, 438-452.

P.-L. Frison, Laboratoire des Géomatériaux, 1'Institut Francilien des Géosciences, Université de Marne la Vallée, 5 blvd Descartes, F-77454 Marne la Vallée Cedex 2, France.

L. Jarlan and E. Mougin, Centre d'Etudes Spatiales de la Biosphère, UMR 5126 UPS-CNRS-CNES-IRD, 18 av. Edouard Belin, BPI 2801, F-31401 Toulouse Cedex 4, France.

N. Philippon, Centre de Recherches de Climatologie, FRE 2740 CNRSUniversité de Bourgogne, 6 blvd Gabriel, BP 27877, F-21078 Dijon Cedex, France. (nphilipp@u-bourgogne.fr) 


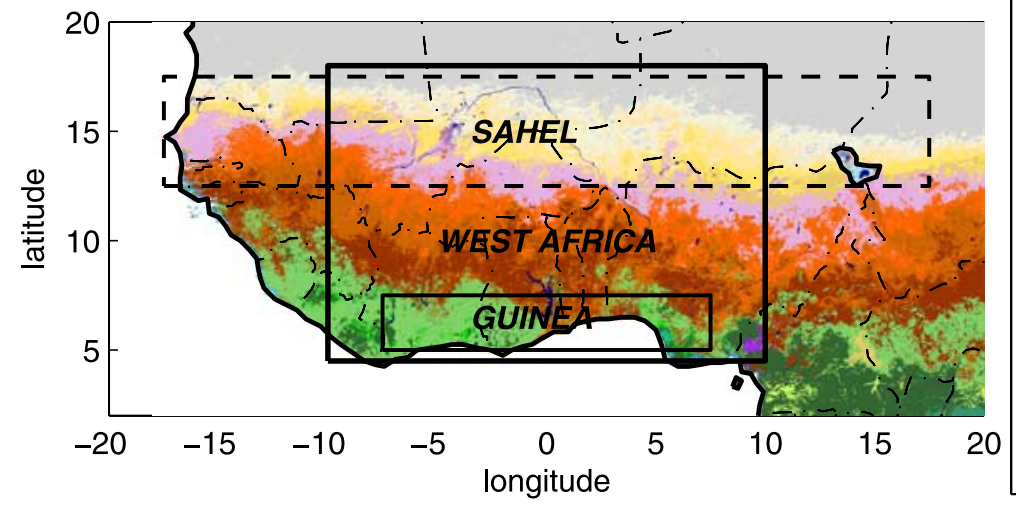

- Closed evergreen lowland forest

- Degraded evergreen lowland forest

- Montane evergreen forest (> $1000 \mathrm{~m})$

- Swamp forest

- Mangrove

1. Mosaic Forest / Croplands

- Mosaic Forest / Savanna

- Closed deciduous forest (Miombo)

- Deciduous woodland

- Deciduous shrubland with sparse trees

- Open deciduous shrubland

- Closed grassland

- Open grassland with sparse shrubs Open grassland

Sparse grassland

Swamp bushland and grassland

Croplands ( $>50 \%)$

- Croplands with open woody vegetation

- Irrigated croplands

- Tree crops

- Bare soil

- Salt hardpans

- Waterbodies

Cities

Figure 1. Land cover map of West Africa (produced as part of the GLC2000 mapping exercise) and location of the West African (thick solid line), Guinean (thin solid line) and Sahelian (thin dashed line) domains studied. 